\title{
Long-term effects of asthma medication on asthma symptoms: an application of the targeted maximum likelihood estimation
}

\author{
Carolin Veit ${ }^{1,2,3}$, Ronald Herrera ${ }^{1,3}$, Gudrun Weinmayr $^{4}$, Jon Genuneit ${ }^{4,5}$, Doris Windstetter ${ }^{1,3}$, Christian Vogelberg ${ }^{6}$,
} Erika von Mutius ${ }^{3,7}$, Dennis Nowak ${ }^{1,3}$, Katja Radon ${ }^{1,3}$, Jessica Gerlich ${ }^{1,3+}$ and Tobias Weinmann ${ }^{1,3^{*}}$ (D)

\begin{abstract}
Background: Long-term effectiveness of asthma control medication has been shown in clinical trials but results from observational studies with children and adolescents are lacking. Marginal structural models estimated using targeted maximum likelihood methods are a novel statistiscal approach for such studies as it allows to account for time-varying confounders and time-varying treatment. Therefore, we aimed to calculate the long-term risk of reporting asthma symptoms in relation to control medication use in a real-life setting from childhood to adulthood applying targeted maximum likelihood estimation.

Methods: In the prospective cohort study SOLAR (Study on Occupational Allergy Risks) we followed a German subsample of 121 asthmatic children (9-11 years old) of the ISAAC II cohort (International Study of Asthma and Allergies in Childhood) until the age of 19 to 24. We obtained self-reported questionnaire data on asthma control medication use at baseline (1995-1996) and first follow-up (2002-2003) as well as self-reported asthma symptoms at baseline, first and second follow-up (2007-2009). Three hypothetical treatment scenarios were defined: early sustained intervention, early unsustained intervention and no treatment at all. We performed longitudinal targeted maximum likelihood estimation combined with Super Learner algorithm to estimate the relative risk (RR) to report asthma symptoms at SOLAR I and SOLAR II in relation to the different hypothetical scenarios.
\end{abstract}

Results: A hypothetical intervention of early sustained treatment was associated with a statistically significant risk increment of asthma symptoms at second follow-up when compared to no treatment at all (RR: 1.51, 95\% Cl: 1.191.83) or early unsustained intervention (RR:1.38, 95\% Cl: 1.11-1.65).

Conclusions: While we could confirm the tagerted maximum likelihood estimation to be a usable and robust statistical tool, we did not observe a beneficial effect of asthma control medication on asthma symptoms. Because of potential due to the small sample size, lack of data on disease severity and reverse causation our results should, however, be interpreted with caution.

Keywords: Adolescents, Asthma, Children, Control medication, Marginal structural models, Targeted-maximum likelihood estimation

\footnotetext{
* Correspondence: tobias.weinmann@med.Imu.de

${ }^{\dagger}$ Jessica Gerlich and Tobias Weinmann contributed equally to this work.

${ }^{1}$ Institute and Clinic for Occupational, Social and Environmental Medicine,

LMU University Hospital Munich, Munich, Germany

${ }^{3}$ Comprehensive Pneumology Center CPC LMU Munich, member of the

German Center for Lung Research (DZL), Munich, Germany

Full list of author information is available at the end of the article
}

(C) The Author(s). 2020 Open Access This article is licensed under a Creative Commons Attribution 4.0 International License, which permits use, sharing, adaptation, distribution and reproduction in any medium or format, as long as you give appropriate credit to the original author(s) and the source, provide a link to the Creative Commons licence, and indicate if changes were made. The images or other third party material in this article are included in the article's Creative Commons licence, unless indicated otherwise in a credit line to the material. If material is not included in the article's Creative Commons licence and your intended use is not permitted by statutory regulation or exceeds the permitted use, you will need to obtain permission directly from the copyright holder. To view a copy of this licence, visit http://creativecommons.org/licenses/by/4.0/ The Creative Commons Public Domain Dedication waiver (http://creativecommons.org/publicdomain/zero/1.0/) applies to the data made available in this article, unless otherwise stated in a credit line to the data. 


\section{Background}

Asthma is a chronic inflammatory disease, which affects the respiratory system and leads to different symptoms varying from one individual to another and across time. These include wheezing, shortness of breath, cough, chest tightness and impaired lung function because of constriction and inflammation of the bronchial system [1]. The disease is ranked as the 16th most leading cause of years lived with disability (YLD) worldwide [2]. Its prevalence varies depending on country [3] as well as on the definition of asthma [4]. Furthermore, asthma is the most common chronic disease among children [5]. According to the ISAAC study, the prevalence of this disease ranges between six and $27 \%$ in adolescents aged between 13 and 14 years [3]. As asthma often develops during childhood, early intervention should aim to prevent a decrease or impaired increase in lung function until adulthood [6].

The pathogenesis of different phenotypes of asthma is still not fully elucidated [7] with guideline interventions in the form of pharmacological treatment mainly targeting the control of symptoms rather than curing the initial cause of the disease [1]. Asthma treatment recommended by the Global Initiative for Asthma (GINA) is divided into reliever medication, which is indicated for acute asthma attacks, and control medication, which aims to control symptoms and prevent asthma exacerbations [1].

Since asthma is a chronic disease, long-term outcomes are of particular interest to evaluate the effectiveness of interventions. Several clinical trials have studied the long-term effect of different asthma medications on symptom control and lung function, finding a positive effect especially for inhaled corticosteroids (ICS) [8-12]. Nevertheless, clinical randomised controlled trials (cRCTs) may not always represent the general population because the study population is highly selected based on various criteria [13]. Consequently, evidence for treatment guidelines should be a combination of results from cRCTs and real-life studies, such as observational studies [14]. However, there are only few observational studies investigating this study question. In some of them, the authors concluded that asthma control did not reach the desired level that better asthma management would increase asthma control $[15,16]$. This emphasises that a positive effect of asthma medication in a cRCT does not necessarily result in a positive effect in real-life circumstances.

To analyse observational data, traditional regression methods are often used. However, standard regression analyses like logistic regression are not suitable in case of time-varying treatment and confounding, which can occur in longitudinal studies [17]. An alternative approach to study longitudinal data in presence of time- varying confounding is provided by structural models [17] estimated using targeted maximum likelihood estimation (TMLE) $[18,19]$. This approach has already been applied to different longitudinal settings and its desirable statistical properties have been shown [20-22]. It allows interpreting the effect of hypothetical intervention scenarios as it is done in randomised controlled trials adjusted for time-varying confounders. The main difference compared to traditional regression analyses is that no assumption about the distribution of the data structure is made [19]. If these assumptions are violated, which is the case when time-varying confounding occurs, traditional regression methods will lead to biased results [19].

To our knowledge, no previous study has investigated the long-term effect of asthma control medication on symptoms using the TMLE approach. Furthermore, only few studies included children and adolescents [23]. Therefore, we aimed to apply this strategy to study the long-term effect of hypothetical asthma treatment regimens on symptoms of children and adolescents. Based on the results of cRCTs, our hypothesis was that early asthma medication should improve symptoms in children and young adults.

\section{Methods}

\section{Study design and study population}

Our cohort consists of a subsample of asthmatic participants of the ISAAC II study in Munich and Dresden, which took place in 1995-1996 and had two follow-ups by SOLAR I in 2002-2003 and by SOLAR II in 20072009. Manuscripts describing the respective study designs are available elsewhere [24-26]. In short, 6399 parents of children aged nine to eleven that were recruited via random sampling filled in a standardised questionnaire for their offspring in ISAAC II (response: 85\%) and 2589 of those children took part in a clinical assessment including spirometry. By the age of 16 to 18 years, 3785 participants of the original ISAAC II cohort filled in the follow-up questionnaire (response: $80 \%$ ). At the second follow-up, 2051 participants aged 19 to 24 years completed the questionnaire (response: $71 \%$ ) with $57 \%$ of them taking part in clinical examinations including spirometry (SOLAR II) (Fig. 1). Out of those 2051 participants, we selected those individuals that were classified as asthmatics at baseline (ISAAC II) as our study population for the present analysis $(n=121$, Fig. 1$)$. This selection is due to the fact that the main interest of this analysis was the effect of asthma medication on asthma symptoms.

The three questionnaires were based on validated items from ISAAC [27] and the European Community Respiratory Health Survey (ECRHS) [28]. They contained questions on sociodemographic data, respiratory symptoms, allergic symptoms, as well as environmental 


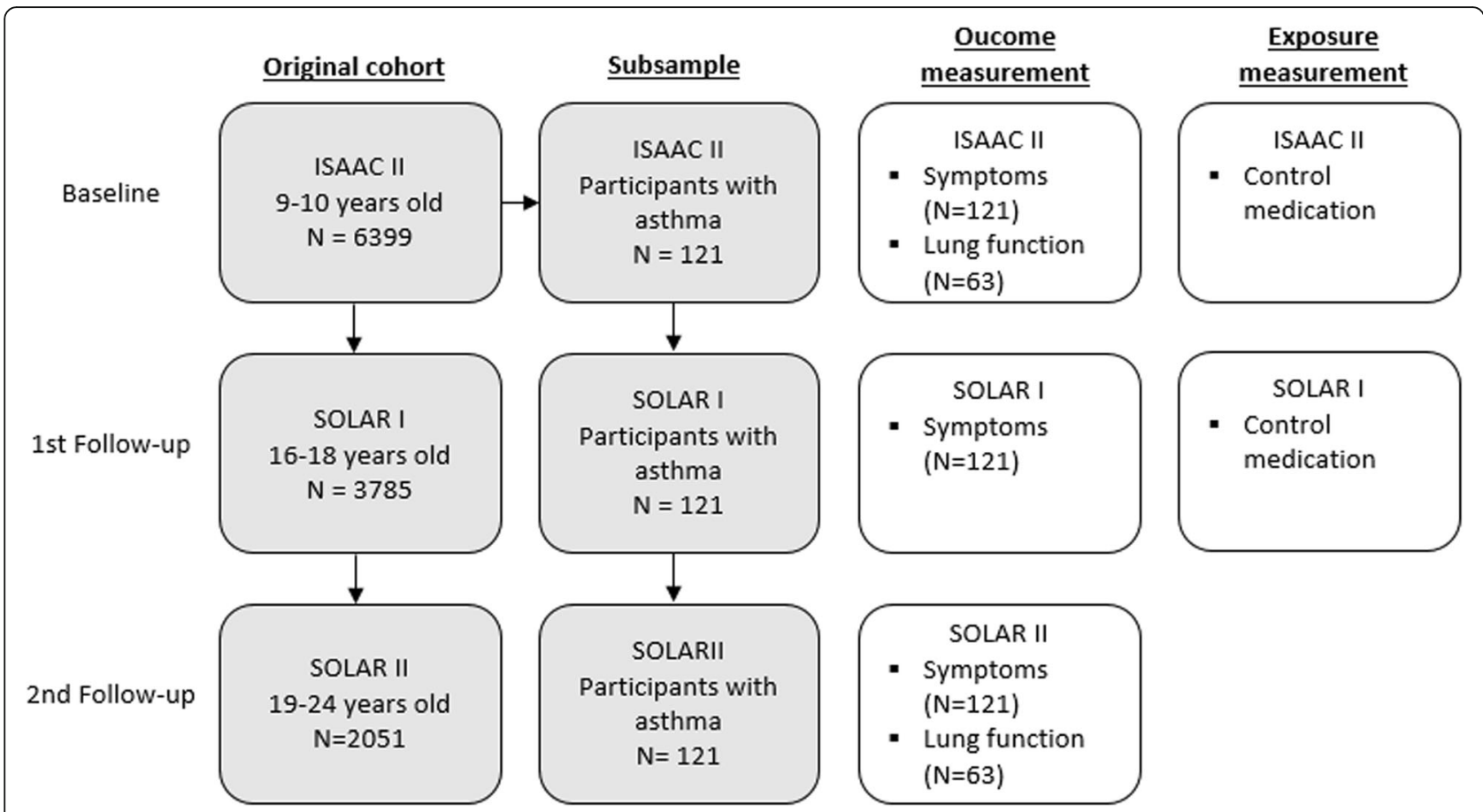

Fig. 1 Flow chart for the original cohort and the subsample of participants with asthma from baseline (ISAAC II) to first follow-up (SOLAR I) and second follow-up (SOLAR II) (grey boxes). Time points for outcome and exposure measurements are shown in the white boxes

and occupational risk factors. Additionally, at baseline and first follow-up, the participants provided selfreported data on medication use in case of respiratory problems. Clinical assessment at ISAAC II and SOLAR II included, among others, spirometry and bronchial hyperresponsiveness testing (BHR) with saline.

\section{Outcome of interest}

Our outcome of interest was the presence of asthmatic symptoms in the previous twelve months. Following the GINA Guideline [1], we defined the following items to measure asthma symptoms: daytime symptoms (cough or wheezing), nighttime symptoms (awaking due to wheezing or breathlessness) and limitation of activity (breathlessness at rest or after physical activity). Data on symptoms were available for all three time points (Fig. 1) and a binary variable was created as either having reported symptoms or not. Reliever medication intake is another criterion of asthma control in the GINA guideline. For SOLAR II it was, however, not measured. Therefore, we only used the symptom criteria of the GINA Guidline.

For sensitivity analysis, we defined lung function as a continuous variable. We calculated the ratio of forced expiratory volume in one second to forced vital capacity $\left(F E V_{1 s} / F V C\right)$, as it is described as an indicator for obstructive airway diseases in the Report of the Global Lung Initiative [29].

\section{Exposure definition}

We defined a binary exposure variable for self-reported control medication intake in the last twelve months (yes versus no). The exposed group contained those who reported the intake of control medication whereas the unexposed group included those who reported no medication use or only reliever medication use. Selfreported medication was assigned to active agents and drug classes based on the Drug Information System from the German Institute of Medical Documentation [30], the Anatomical Therapeutic Chemical (ATC) classification system [31] and the GINA guideline [1] (Table 1).

\section{Hypothetical intervention scenarios}

We defined different types of hypothetical intervention scenarios (Table 2). First, we were interested in a hypothetical scenario in which none of the participants had taken control medication neither at ISAAC II nor at SOLAR I (Intervention 1: "0,0"). Hypothetical Intervention 2 consisted of patients taking control medication only at ISAAC II ("1,0"). Intervention 3 describes a scenario in which everyone had taken control medication at both time points ("1,1"). No intervention means that the pattern of control medication intake is as it occurs in 
Table 1 Classification of reliever medication and control medication based on active agents and drug classes

\begin{tabular}{lll}
\hline Reliever medication & Short-acting $\beta$ 2-agonists (SABA) & Active agent \\
& Combinations of SABA and mast-cell stabilizers & Terbutaline, salbuatmol, tulobuterol, fenoterol, epinephrine/ adrenaline \\
& Short-acting muscarinic antagonists (SAMA) & Ipratropium bromide \\
& Combinations of SABA and SAMA & Fenoterol + ipratropium bromide \\
Control medication & Inhaled corticosteroids (ICS) & Beclomethasone, fluticasone, budesonide, dexamethasone, flunisolide \\
& Long-acting $\beta 2$-agonists (LABA) & Formoterol, salmeterol, clenbuterol \\
& Combinations of ICS and LABA & Fluticasone + salmeterol, formoterol + budesonide \\
& Leukotriene receptor antagonists & Montelukast \\
& Systemic corticosteroids & Betamethasone, cortisone, prednisone, prednisolone, mometasone \\
& Mast-cell-stabilizer & Cromocligic acid \\
Methylxanthines & Methylxanthines, aminophylline \\
\hline
\end{tabular}

the data. We chose these types of interventions because we could then later compare the effects of sustained treatment (Intervention 3), early but not sustained treatment (Imtervention 2), and no treatment at all (Intervention 1). We did not include a scenario for late intervention because we were interested in the longterm effect of early intervention.

\section{Potential confounders}

The selection of the confounders was based on prior knowledge from earlier studies and their potential relation ship was depicted in a causal diagram (Fig. 2). To this end, we differentiated between baseline confounders (W) and time-varying confounders (L1, L2, L3) at ISAA C II, SOLAR I, SOLAR II. In particular, as potential baseline confounders we considered sex (male vs. female), parental socio-economic status (high, vs. low), study center (Munich or Dresden) and parental asthma history (yes vs. no) which might be related to asthma treatment $(\mathrm{A})$ and the outcome $(\mathrm{Y})$. As time-varying binary confounders (L), we included current hay fever (yes vs. no; ever diagnosed hay fever by a doctor and itchy eyes and runny nose without cold in the last 12 months), physical activity (yes vs. no; participant reports excercising at least once per week), smoking status (smoker vs. non-smoker), second hand smoke (yes vs. no) and overweight (body mass index (bmi) $>=25 \mathrm{~kg} / \mathrm{m}^{2}$ vs. bmi $<$ $25 \mathrm{~kg} / \mathrm{m}^{2}$ ). Furthermore, we took age into account as a continuous covariate [32-35]. Additionally, for the sensitivity analysis regarding the outcome, we considered height as continuous covariate because it is a predictor of lung function.

\section{Statistical analysis}

Marginal structural models (MSM) are a suitable statistical approach for longitudinal data in which timevarying treatment and confounding occurs [17]. Therefore, we used TMLE combined with Super Learner algorithm [36] to estimate the relative risk (RR) to report asthma symptoms at SOLAR I and SOLAR II in relation to the different hypothetical scenarios (Table 2).

To identify causal effects via MSM it is necessary to state certain assumptions. Firstly, this comprises the consistency assumption [37], which means that the observed outcome (asthma symptoms yes vs. no) of an individual, taking control medication or not is the same as the counterfactual outcome under control medication or no control medication. Secondly, we assume conditional exchangeability [38], indicating that we included all reasonably possible confounders. The third assumption is positivity [39], stating that there is a probability of greater than zero to be exposed given all combinations of covariates.

For the analyses, we used $\mathrm{R}$ version 3.4 .3 [40], the package ltmle version 1.0-1 [41] and SuperLearner version 2.0-23 [42]. Furthermore, we assumed that missing values were missing at random. Therefore, we performed multiple imputation ( $\mathrm{m}=5$ imputations) by using the $\mathrm{R}$

Table 2 Description of defined hypothetical intervention scenarios

\begin{tabular}{ll}
\hline Type of Intervention & Description \\
\hline Intervention $1(0,0)$ & No one takes control medication neither at ISAAC II nor at SOLAR I \\
Intervention $2(1,0)$ & Everyone takes control medication at ISAAC II but not at SOLAR I \\
Intervention $3(1,1)$ & Everyone takes control medication both at ISAAC II and SOLAR I \\
No Intervention & Control medication is taken as it was observed in the data \\
\hline
\end{tabular}




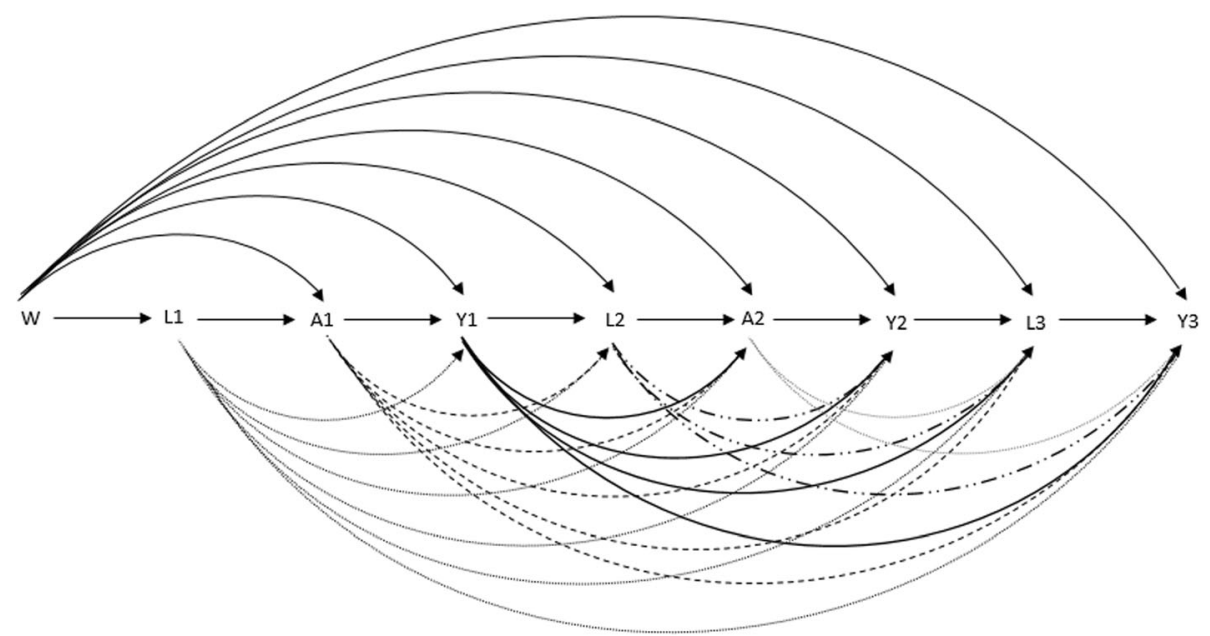

Fig. 2 Potential causal relationship between the included covariates. Legend: $W=$ Baseline covariates (ses, sex, study centre, parental asthma history); L1, L2, L3 = time varying confounders at ISAAC II, SOLAR I, SOLAR II (hay fever, overweight, smoking, passive smoking, age); A1, A2 = Treatment at ISAAC II and SOLAR I; Y1, Y2, Y3 = intermediate outcomes and final outcome (asthma symptoms) at ISAAC II, SOLAR I, SOLAR II

package mice version 2.46.0 [43] and applying Rubin's rule [44] to get combined estimators for the relative risks including confidence intervals from the imputed data.

\section{Sensitivity analyses}

Spirometry data was available for ISAAC II and SOLAR II (Fig. 1; Additional file 1). Furthermore, the study population for clinical examination comprised only 63 participants because not all of the participants agreed to take part in clinical measurements. However, we performed a sensitivity analysis with lung function $\left(\mathrm{FEV}_{1 \mathrm{~s}} /\right.$ FVC) as outcome to make a comparison of the estimation approach using self-reported symptoms as outcome with an objective measurement. In contrast to the main analysis in which we calculated relative risks, we calculated the additive treatment effect for the outcome lung function. This was necessary because of the $\mathrm{FEV}_{1 \mathrm{~s}} / \mathrm{FVC}$ ratio being a continuous variable instead of a binary one.

In addition, we performed a sensitivity analysis in which we classified reliever medication and control medication as exposure variales and considered nonexposed participants as those not taking any medication. This additional classification was done in order to examine if the effect of control medication changes when adding reliever medication to the exposed group.

\section{Results}

The total study sample consisted of 121 participants. There were more male participants in the study population $(66 \%)$ than females and about half of the children's parents had a high socio-economic status. A fifth of the participants' parents have had a history of asthma. Moreover, about a quarter of the study population had current hay fever at baseline, the prevalence of which increased over the two follow-ups. In ISAAC II, 116 participants reported having had asthma symptoms during the last twelve months. This number decreased to 80 and 79 in the two follow-ups. Regarding control medication intake, the number of participants reporting such intake fell from more than $50 \%$ at ISAAC II to only $15 \%$ at SOLAR II. Consequently, we observed a rise in the percentage of individuals indicating no medication intake at at all from $19 \%$ at ISAAC II to $57 \%$ at SOLAR I. With respect to potential confounders, we observed that the number of individuals exposed to passive smoke increased from about a quarter of the participants at baseline to almost $50 \%$ at SOLAR I and II. It is also worthwhile to mention that between the first and the second follow-up more participants became overweight (9\% vs. $23 \%$ ) (Table 3 ).

About one third of the population reported no control medication intake neither in ISAAC II nor in SOLAR I. About $40 \%$ reported to take control medication only in ISAAC II but not in SOLAR I, and only 15\% took control medication both in ISAAC II and SOLAR I (Table 4). No data on specific medication use was available for SOLAR II.

We observed a statistically significant risk increment, adjusted for all in the methods section mentioned confounders, between control medication use and asthma symptoms at SOLAR I when the two extreme intervention scenarios (Intervention 1 and 3) were compared. In other words, there would have been an increased relative risk of 1.37 (95\% CI: 1.02-1.73) to report asthma symptoms at SOLAR I had all participants taken control medication at both time points vs. had no one taken control medication at both time points. This association was stronger when we calculated the outcome until 
Table 3 Characteristics of the study participants at the three time points ISAAC II, SOLAR I and SOLAR II $(N=121)$

\begin{tabular}{llll}
\hline Variables & ISAAC II & SOLAR I & SOLAR II \\
\hline Age, mean $\left(\mathrm{sd}^{\mathrm{a}}\right)$ & $9.6(0.56)$ & $17.0(0.59)$ & $22.3(0.69)$ \\
$\mathrm{NAs}$ & 0 & 0 & 0 \\
Asthma symptoms, N (\%) & $116(95.9)$ & $80(66.1)$ & $79(65.3)$ \\
Yes & 0 & $2(1.7)$ & $1(0.8)$ \\
NAs & & & $18(14.9)$ \\
Control medication, N (\%) & $67(55.4)$ & $4(3.3)$ & n.m. \\
Yes & $11(9.1)$ & &
\end{tabular}

Only reliever medication

$\begin{array}{lll}\text { Yes } & 19(15.7) & 30(24.8) \\ \text { NAs } & 11(9.1) & 4(3.3)\end{array}$

No asthma medication intake at all

Yes $24(19.8)$

$69(57.0)$

NAs

Study center, N (\%)

$\begin{array}{ll}\text { Munich } & 68(56.2) \\ \text { NAs } & 0 \\ \text { Sex } & \\ \text { Male } & 80(66.1) \\ \text { NAs } & 0 \\ \text { SES }{ }^{d} \text { parents, N (\%) } & \\ \text { High } & 63(52.1) \\ \text { NAs } & 1(0.8)\end{array}$

Asthma history of parents ${ }^{\mathrm{e}}, \mathrm{N}(\%)$

Yes

NAs

Passive smoking ${ }^{f}, \mathrm{~N}(\%)$

Yes $32(26.4)$

NAs

Current smoker ${ }^{\mathrm{g}}, \mathrm{N}(\%)$

Yes

n.m.

NAs

Physical activity ${ }^{\mathrm{h}}, \mathrm{N}(\%)$

Yes n.m.
NAs

Overweight ${ }^{\mathrm{i}}$

yes n.m.

NAs

Current hay fever', N (\%)

Abbreviations and comments. ${ }^{a}$ Sd standard deviation, ${ }^{b} \mathrm{NAs}$ missing values, ${ }^{\mathrm{C}} \mathrm{n} . \mathrm{m}$. not measured, ${ }^{\mathrm{d}} \mathrm{SES}$ socio-economic status (high if one parent has at least higher secondary education or university degree); ${ }^{~} Y e s$ if at least one parent has ever had asthma; ${ }^{f}$ ISAAC II: passive smoking of child if parents are current smokers, SOLAR I/SOLAR II: Yes if exposition to passive smoke per day $>0,5 \mathrm{~h}$; ${ }^{9}$ Current smoker $=$ smoked ever for 1 year and smoked in the last month; ${ }^{\mathrm{h}}$ Yes if participant reports doing sport at least once per week; 'Yes if body mass index $>=25$; ' ${ }^{j}$ Yes if ever diagnosed hay fever by a doctor and itchy eyes and runny nose without cold in the last 12 months 
Table 4 Number and percentage of participants with asthma following the treatment interventions of control medication

\begin{tabular}{lcc}
\hline Intervention $\mathbf{1}(\mathbf{0}, \mathbf{0})$ & Intervention 2 (1,0) & Intervention $\mathbf{3}(\mathbf{1}, \mathbf{1})$ \\
\hline $42(34.7)$ & $48(39.7)$ & $18(14.9)$ \\
\hline
\end{tabular}

Comments: Intervention $1(0,0)$ no control medication intake neither at ISAAC II nor at SOLAR I; Intervention $2(1,0)$ control medication only at ISAAC II not at SOLAR I; Intervention $3(1,1)$ control medication intake at ISAAC II and SOLAR I

SOLAR II (adjusted RR: 1.51, 95\% CI: 1.19-1.83). Additionally, the effect was similar (adjusted RR: 1.38, 95\% CI: 1.11-1.65) when we compared the sustained intervention (first and second time point) to the early Intervention (only first time point) and calculated until SOLAR II, but not until SOLAR I. For the other comparisons, there were no statistically significant associations (Table 5).

Adding reliever medication to the control medication as exposure variable, there was a statistically significant risk increment when we compared sustained intervention with early intervention (SOLAR I: adjusted RR = 1.61, 95\% CI: 1.32-1.90; SOLAR II: 1.32, 95\% CI: $1.03-$ 1.62) (Additional file 2).

Using spirometric results as outcome, we calculated the adjusted additive treatment effect (ATE) on $\mathrm{FEV}_{1 \mathrm{~s}} / \mathrm{FVC}$ ratio as mean difference between ISAAC II and SOLAR II. We observed a statistically significant reduction of the adjusted $\mathrm{FEV}_{1 \mathrm{~s}} / \mathrm{FVC}$ ratio of $-4.48 \%$ (CI $=-6.97 \%$; $1.99 \%)$ when we compared sustained intervention to early intervention. This indicates that if everyone had taken control medication at both time points compared to if everyone had taken control medication only at ISAAC II, the lung function (measured as $\mathrm{FEV}_{1 \mathrm{~s}} / \mathrm{FVC}$ ratio) would have decreased by $4.48 \%$. A similar, but weaker association was found when we calculated lung function for the exposure of the sensitivity analysis (adjusted ATE $=-2.82 \%$, CI -4.93\%; - 0.71\%) (Additional files 3 and 4).

\section{Discussion}

In the present analysis, we applied the targeted maximum likelihood estimation approach to calculate the relative risk to report asthma symptoms in relation to asthma control medication use in a population-based longitudinal setting with twelve years of follow-up. By using a Marginal Structural Models approach, we could account for time-varying treatment and confounding. We observed an increased relative risk of asthma symptoms following a hypothetical sustained intervention of control medication when compared tono treatment at all or early unsustained intervention.

There are several possible explanations why in our study population the intake of asthma control medication tended to be associated with still reporting symptoms on a long-term follow-up. Firstly, it could be that pharmacological treatment used for symptom control cannot alter the underlying disease process $[1,45]$. This was, for example, shown in an analysis of German routine data where immunotherapy, which targets the immunological cause of allergic asthma, was more beneficial regarding the course of asthma than asthma medications [46]. Additionally, we followed participants for twelve years. Hence, our results represent long-term effects, which are not necessarily comparable to positive effects of clinical trials with shorter follow-up periods [8-12]. Hence, it may be especially interesting if in the future clinical trials could follow-up their participants for longer periods as to ensure a better comparability with long-standing observational studies such as ours (being fully aware though that such clinical trials with long follow-up periods would constitute a very expensive endeavour).

Another interpretation could be that individuals with specific phenotypes or highly severe forms of asthma do not respond to the treatment [47]. Consequently, their asthma symptoms may worsen despite the intake of preventive asthma mediaction. One could also argue that their disease status would even worsen faster if not having taken any medication. One should also take into account that patients with more severe symptoms are more likely to take preventive medicine in comparison to patients with less severe phenotypes. Another

Table 5 Associations between control medication use and asthma symptoms at SOLAR I and SOLAR II obtained through TMLE

\begin{tabular}{lll}
\hline $\begin{array}{l}\text { Treatment scenario (control } \\
\text { medication use) }\end{array}$ & $\begin{array}{l}\text { Adjusted relative risk to report asthma symptoms } \\
\text { at SOLAR I (95\% CI) }\end{array}$ & $\begin{array}{l}\text { Adjusted relative risk to report asthma symptoms } \\
\text { at SOLAR II }(\mathbf{9 5 \%} \mathbf{C l})\end{array}$ \\
\hline $\begin{array}{l}\text { Intervention } 3 \text { vs. Intervention } 1 \\
(1,1)(0,0)\end{array}$ & $1.37(1.02 ; 1.73)$ & $1.51(1.19 ; 1.83)$ \\
$\begin{array}{l}\text { Intervention } 3 \text { vs. No Intervention } \\
(1,1)\end{array}$ & $1.21(0.94 ; 1.49)$ & $1.28(1.00 ; 1.57)$ \\
$\begin{array}{l}\text { Intervention } 3 \text { vs. Intervention } 2 \\
(1,1)(1,0)\end{array}$ & $1.24(0.96 ; 1.52)$ & $1.38(1.11 ; 1.65)$ \\
$\begin{array}{l}\text { Intervention } 2 \text { vs. Intervention } 1 \\
(1,0)(0,0)\end{array}$ & $1.09(0.79 ; 1.40)$ & $1.08(0.76 ; 1.41)$ \\
$\begin{array}{l}\text { Intervention } 2 \text { vs. No Intervention } \\
(1,0)\end{array}$ & $0.98(0.73 ; 1.23)$ & $0.92(0.64 ; 1.21)$ \\
\hline
\end{tabular}


important aspect might be insufficient adherence to the treatment. Several studies have shown that asthma patients frequently do not use their medication as often as needed or not in the right manner [48-50]. This effect may especially occur when physicians do not apply recommended prescription guidelines properly or may have insufficient knowledge about preventive measures and diagnosis [51]. In this context, it also needs to be highlighted that our findings are in line with other studies observing low asthma control despite control medication use $[15,16,52]$. On the other hand, a recently published large-scale cohort study from the United States did observe a beneficial effect of asthma medication, specifically of inhaled corticosteroids [53]. What may also be taken into account is the fact that there is some evidence that the use of $\beta$-agonists and other bronchodilators can lead to paradoxical bronchoconstriction [54]. To the best of our knowledge, however, such effects are mainly associated with short-acting $\beta$ agonists which we classified as reliever medication [55]. Since our main exposure was the use of control medication, we thus expect any such effect to have a rather low impact on the results of our study.

We acknowledge that our study may have several limitations. Due to the small sample size of 121 asthmatic children at baseline, we could not divide the study population into subgroups for comparisons such as female/male or classification by asthma severity. We also had no classification of asthma severity beyond medication. We thus could not adjust our analyses for asthma severity so that we cannot rule out that our results are influenced by confounding due to disease severity. This could have biased our results in the way that participants with more severe asthma are also more likely to take control medication. Consequently, the risk increment that we found could be explained by reverse causation. Not taking into account sex differences could lead to ignoring potential effect modification of treatment effect by sex. Furthermore, also because of the sample size, we could not differentiate between different groups of exposure referring to different drugs. To be able to calculate the long-term effect of specific medications, future studies with larger sample sizes are thus needed. The binary classification of the exposure group could have also led to a violation of the abovementioned consistency assumption, meaning that not all types of asthma medication have the same effect and not all asthmatic people respond similarly to the treatment. Nevertheless, when we performed sensitivity analyses for the exposure, the results seemed to be robust, demonstrating on the other hand the robustness of the TMLE approach. Moreover, by defining binary variables we could be more confident not violating the positivity assumption. Another limitation is that our outcome is not comparable to standardised measures of asthma control such as the
Asthma Control Questionnaire (ACQ) [56] or the Asthma Control Test (ACT) [57] because it is based on data from the ISAAC study in which symptom frequency was asked for the last twelve months and not for 1 month. In this context, we also acknowledge that the time period between the baseline and the first follow-up was relativel large, and we cannot entirely be sure how many changes in their patterns of medication use some individuals may have had here and there. Comparison to other study populations should also be made with caution because our sample is restricted to children and young adults. Moreover, Vermeire and colleges found a variation in guideline adherence by doctors of different European countries [16]. Hence, generalisability to populations outside of Germany is limited. We assume that recall bias is not likely to have occurred because asthma is a chronic disease with regular treatment so that we assume participants to be able to correctly report if they currently had the disease or not. What concerns selection bias, former analyses of the SOLAR study have shown that this type of bias does not seem to play a major role in this study [58].

The strengths of our study are the prospective and observational design that provides a more realistic reflection of asthmatic children and adolescents than randomised controlled trials [13, 14]. Most notably, to our knowledge, this one of the first studies in this field to apply the statistical method of targeted maximum likelihood estimation. This tool is especially powerful to address the issue of time-varying confounding and treatment, thus being a suitable and up-to-date statistical approach and ensuring less bias by model miss specification and more power, despite a small sample size [19]. The results of the various analyses including the sensitivity analyses presented in the present manuscript confirm the usability and robustness of this method.

Altogether, our results suggest that treatment of asthma on a population level still can be optimised. Ideally, lung function should not decrease under treatment, but this was the case in our results. Additional targeted therapies may thus be needed for those patients who do not respond to treatment [59]. Moreover, intervention strategies, which elevate adherence to guidelines by patients and doctors might be measures to ensure that control medication has a more beneficial effect [60]. Finally, additional non-pharmacological interventions such as trigger-avoidance, smoking reduction or physical activity should be considered to improve symptoms of asthmatic individuals [6].

\section{Conclusion}

While we could confirm the tagerted maximum likelihood estimation to be a usable and robust statistical tool, from a clinical perspectice we did not observe the 
desired beneficial effect of asthma control medication on asthma symptoms. Despite the suitability of our statistical methods, our results may, however, still be influenced by the potential impact of confounding by disease severity and additional limitations such as the small sample size or reverse causation. Our results should thus be interpreted with caution.

\section{Supplementary Information}

The online version contains supplementary material available at https://doi. org/10.1186/s12874-020-01175-9.

Additional file 1: Characteristics of the study participants for the sensitivity analysis at the three time points ISAAC II, SOLAR I and SOLAR II (non-imputed data); $N=63$.

Additional file 2:. Associations between asthma medication use and asthma symptoms at SOLAR I and SOLAR II obtained through TMLE.

Additional file 3:. Additive treatment effect of control medication on lung function, obtained through Marginal Structural Models.

Additional file 4:. Additive treatment effect of asthma medication on lung function, obtained through marginal structural models.

\section{Abbreviations}

ACQ: Asthma Control Questionnaire; ACT: Asthma Control Test; ATC: Anatomical Therapeutic Chemical classification system; BHR: Bronchial hyperresponsiveness; Cl: Confidence interval; CRCTs: Clinical randomized controlled trials; ECRHS: European Community Respiratory Health Survey; FEV 1 : Forced expiratory volume in one second; FVC: Forced vital capacity; GINA: Global Initiative for Asthma; ICS: Inhaled corticosteroids; ISAA C: International Study of Asthma and Allergies in Childhood; MSM: Marginal structural models; RR: Relative risk; SOLAR: Study on Occupational Allergy Risks; YLD: Years lived with disability

\section{Acknowledgments}

We cordially thank all study participants.

\section{Authors' contributions}

CaV, TW, JGer, RH, GW, JGen, DW, CV, EvM, DN and KR all made substantial contributions to conception and design of the study and acquisition, analysis, and/or interpretation of data. CaV, TW, JGer and KR drafted the manuscript. All authors contributed in revising it critically for important intellectual content and have given their final approval of the version submitted for consideration for publication.

\section{Funding}

The ISAAC Phase Two study in Dresden and Munich was funded by the German Ministry of Education and Research (01 EE 9411-3). The SOLAR I study was supported by the German Ministry for Economy and Labour. The SOLAR II study was funded by the German Federal Institute for Occupational Safety and Health and the German Ministry of Labour and Social Affairs. The funding bodies had no role in the design of the study or in the analysis and interpretation of the data. Open Access funding enabled and organized by Projekt DEAL.

\section{Availability of data and materials}

The datasets used and/or analysed during the current study are available from the corresponding author on reasonable request.

\section{Ethics approval and consent to participate}

The Ethical Committees of the Medical Faculty of the University of Dresden the Bavarian Chamber of Physicians and the University of Ulm approved all three phases of the study. All included participants gave written informed consent.

\section{Consent for publication}

Not applicable.

\section{Competing interests}

DN holds stocks of pharmaceutical companies selling asthma medication, and has received fees (Mundipharma, GSK, Boehringer) for presentations on asthma management. All other authors declare that they have no conflict of interest.

\section{Author details}

${ }^{1}$ Institute and Clinic for Occupational, Social and Environmental Medicine, LMU University Hospital Munich, Munich, Germany. ${ }^{2}$ Department of Medical Informatics, Biometry and Epidemiology (IBE), Ludwig-Maximilian University Munich (LMU), Munich, Germany. ${ }^{3}$ Comprehensive Pneumology Center CPC LMU Munich, member of the German Center for Lung Research (DZL), Munich, Germany. ${ }^{4}$ Institute of Epidemiology and Medical Biometry, UIm University, Ulm, Germany. ${ }^{5}$ Paediatric Epidemiology, Hospital for Children and Adolescents, University of Leipzig Medical Center, Leipzig, Germany.

${ }^{6}$ Paediatric Department, University Hospital Carl Gustav Carus Dresden, TU Dresden, Dresden, Germany. ${ }^{7}$ Dr. v. Haunersches Kinderspital, LMU University Hospital Munich, Munich, Germany.

Received: 9 July 2020 Accepted: 23 November 2020

Published online: 16 December 2020

\section{References}

1. Global Initiative for Asthma. Global Strategy for Asthma Management and Prevention. www.ginasthma.org. Accessed 6 June 2019.

2. Soriano JB, Abajobir AA, Abate $\mathrm{KH}$, et al. Global, regional, and national deaths, prevalence, disability-adjusted life years, and years lived with disability for chronic obstructive pulmonary disease and asthma, 1990-2015: a systematic analysis for the global burden of disease study 2015. Lancet Respir Med. 2017;5(9):691-706.

3. Pearce N, Aït-Khaled N, Beasley R, et al. Worldwide trends in the prevalence of asthma symptoms: phase III of the international study of asthma and allergies in childhood (ISAAC). Thorax. 2007:62(9):758-66.

4. Sá-Sousa A, Jacinto T, Azevedo LF, et al. Operational definitions of asthma in recent epidemiological studies are inconsistent. Clin Transl Allergy. 2014;4: 24

5. Asher I, Pearce N. Global burden of asthma among children. Int J Tuberc Lung Dis. 2014;18(11):1269-78.

6. Beasley $R$, Semprini A, Mitchell EA. Risk factors for asthma: is prevention possible? Lancet. 2015;386(9998):1075-85.

7. Hirose M, Horiguchi T. Asthma phenotypes. J Gen Fam Med. 2017;18(5):18994.

8. Sorkness CA, Lemanske RF, Mauger DT, et al. Long-term comparison of 3 controller regimens for mild-moderate persistent childhood asthma: the pediatric asthma controller trial. J Allergy Clin Immunol. 2007;119(1):64-72.

9. Papi A, Marku B, Scichilone N, et al. Regular versus as-needed budesonide and formoterol combination treatment for moderate asthma: a noninferiority, randomised, double-blind clinical trial. Lancet Respir Med. 2015; 3(2):109-19.

10. Maspero J, Guerra F, Cuevas F, et al. Efficacy and tolerability of salmeterol/ fluticasone propionate versus montelukast in childhood asthma: a prospective, randomized, double-blind, double-dummy, parallel-group study. Clin Ther. 2008;30(8):1492-504

11. Reddel HK, Busse WW, Pedersen S, et al. Should recommendations about starting inhaled corticosteroid treatment for mild asthma be based on symptom frequency: a post-hoc efficacy analysis of the START study. Lancet. 2017:389(10065):157-66.

12. Loymans RJB, Gemperli A, Cohen J, et al. Comparative effectiveness of long term drug treatment strategies to prevent asthma exacerbations: network meta-analysis. BMJ. 2014;348:g3009.

13. Herland $\mathrm{K}$, Akselsen J-P, Skjønsberg $\mathrm{OH}$, et al. How representative are clinical study patients with asthma or COPD for a larger "real life" population of patients with obstructive lung disease? Respir Med. 2005;99(1):11-9.

14. Price D, Brusselle G, Roche N, et al. Real-world research and its importance in respiratory medicine. Breathe (Sheff). 2015;11(1):26-38.

15. Chapman KR, Boulet LP, Rea RM, et al. Suboptimal asthma control: prevalence, detection and consequences in general practice. Eur Respir J. 2008:31(2):320-5.

16. Vermeire PA, Rabe KF, Soriano JB, et al. Asthma control and differences in management practices across seven European countries. Respir Med. 2002; 96(3):142-9. 
17. Robins JM, Hernán MA, Brumback B. Marginal structural models and causal inference in epidemiology. Epidemiology. 2000;11(5):550-60.

18. Petersen M, Schwab J, Gruber S, et al. Targeted maximum likelihood estimation for dynamic and static longitudinal marginal structural working models. J Causal Inference. 2014;2(2):147-85.

19. van der Laan MJ, Rose S. Targeted learning. New York: Springer New York; 2011.

20. Kreif N, Tran L, Grieve R, et al. Estimating the comparative effectiveness of feeding interventions in the pediatric intensive care unit: a demonstration of longitudinal targeted maximum likelihood estimation. Am J Epidemiol. 2017;186(12):1370-9.

21. Decker AL, Hubbard A, Crespi CM, et al. Semiparametric estimation of the impacts of longitudinal interventions on adolescent obesity using targeted maximum-likelihood: accessible estimation with the Itmle package. J Causal Inference. 2014;2(1):95-108.

22. Schnitzer ME, van der Laan MJ, Moodie EEM, et al. Effect of breastfeeding on gastrointestinal infection in infants: a targeted maximum likelihood approach for clustered longitudinal data. Ann Appl Stat. 2014;8(2):703-25.

23. Tamesis GP, Covar RA. Long-term effects of asthma medications in children. Curr Opin Allergy Clin Immunol. 2008;8(2):163-7.

24. Weiland SK, Björkstén B, Brunekreef B, et al. Phase II of the international study of asthma and allergies in childhood (ISAAC II): rationale and methods. Eur Respir J. 2004;24(3):406-12.

25. Heinrich S, Peters A, Kellberger J, et al. Study on occupational allergy risks (SOLAR II) in Germany: design and methods. BMC Public Health. 2011;11: 298.

26. Weiland SK, von Mutius E, Hirsch T, et al. Prevalence of respiratory and atopic disorders among children in the east and west of Germany five years after unification. Eur Respir J. 1999;14(4):862-70.

27. Asher MI, Keil U, Anderson HR, et al. International study of asthma and allergies in childhood (ISAAC): rationale and methods. Eur Respir J. 1995;8(3): 483-91.

28. Ten BP. Years of research on asthma in Europe. The European Community respiratory health survey. Rev Epidemiol Sante Publique. 1998;46(6):491-6.

29. Quanjer PH, Stanojevic S, Cole TJ, et al. Multi-ethnic reference values for spirometry for the 3-95-yr age range: the global lung function 2012 equations. Eur Respir J. 2012;40(6):1324-43.

30. German Institute of Medical Documentation and Information. Drug Information System. http://www.dimdi.de/dynamic/en/db/recherche/index. htm. Accessed 6 June 2019.

31. WHO Collaborating Centre for Drug Statistics Methodology. ATC/DDD Index 2018. https://www.whocc.no/atc_ddd_index. Accessed 6 June 2019.

32. de Groot EP, Nijkamp A, Duiverman EJ, et al. Allergic rhinitis is associated with poor asthma control in children with asthma. Thorax. 2012;67(7):582-7.

33. Chatkin JM, Dullius CR. The management of asthmatic smokers. Asthma Res Pract. 2016;2:10.

34. Cope SF, Ungar WJ, Glazier RH. Socioeconomic factors and asthma control in children. Pediatr Pulmonol. 2008;43(8):745-52.

35. Speck AL, Baptist AP. Physical activity, BMI, and asthma control among adolescents: a cross-sectional analysis. J Allergy Clin Immunol. 2013;131(2): AB106.

36. van der Laan MJ, Polley EC, Hubbard AE. Super learner. Stat Appl Genet Mol Biol. 2007;6:Article25.

37. Cole SR, Frangakis CE. The consistency statement in causal inference: a definition or an assumption? Epidemiology. 2009;20(1):3-5.

38. Greenland S, Robins JM. Identifiability, exchangeability, and epidemiological confounding. Int J Epidemiol. 1986;15(3):413-9.

39. Petersen ML, Porter KE, Gruber S, et al. Diagnosing and responding to violations in the positivity assumption. Stat Methods Med Res. 2012;21(1): 31-54.

40. R Core Team. R: A Language and Environment for Statistical Computing; https://www.R-project.org. Accessed 6 June 2019.

41. Lendle SD, Schwab J, Petersen ML, et al. Itmle An R Package Implementing Targeted Minimum Loss-Based Estimation for Longitudinal Data. J Stat Softw. 2017:81(1).

42. Package 'SuperLearner'. https://CRAN.R-project.org/package=SuperLearner. Accessed 6 June 2019.

43. van Buuren S, Groothuis-Oudshoorn K. mice Multivariate Imputation by Chained Equations in R. J Stat Softw. 2011;45(3).

44. Rubin DB. Multiple imputation for nonresponse in surveys. Hoboken, N.J: John Wiley; 2011.
45. Jutel M. Allergen-specific immunotherapy in asthma. Curr Treat Options Allergy. 2014;1(2):213-9.

46. Weschenfelder A-K, Klimek L, Mülleneisen N, et al. Course of respiratory allergy by treatment strategy based on German routine data. Allergo J Int. 2017;26(6):195-203.

47. Chung KF, Wenzel SE, Brozek JL, et al. International ERS/ATS guidelines on definition, evaluation and treatment of severe asthma. Eur Respir J. 2014; 43(2):343-73.

48. Chan AHY, Stewart AW, Foster JM, et al. Factors associated with medication adherence in school-aged children with asthma. ERJ Open Res. 2016;2(1).

49. Hasford J, Uricher J, Tauscher M, et al. Persistence with asthma treatment is low in Germany especially for controller medication - a population based study of 483,051 patients. Allergy. 2010;65(3):347-54.

50. Krishnan JA, Bender BG, Wamboldt FS, et al. Adherence to inhaled corticosteroids: an ancillary study of the childhood asthma management program clinical trial. J Allergy Clin Immunol. 2012;129(1):112-8.

51. Lingner $H$, Karsch-Völk M, Piepenschneider D, et al. General Practitioners' and Trainees' knowledge of the asthma guidelines in Germany: a crosssectional survey. Qual Prim Care. 2016;24(1):1-7.

52. Vähätalo I, IImarinen $P$, Tuomisto LE, et al. Inhaled corticosteroids and asthma control in adult-onset asthma: 12-year follow-up study. Respir Med. 2018;137:70-6.

53. McGeachie MJ, Wang AL, Lutz SM, et al. Real-life patterns of exacerbations while on inhaled corticosteroids and long-acting Beta agonists for asthma over 15 years. J Clin Med. 2020;9:819.

54. Cocchetto DM, Sykes RS, Spector S. Paradoxical bronchospasm after use of inhalation aerosols: a review of the literature. J Asthma. 1991;28(1):49-53.

55. Magee JS, Pittman LM, Jette-Kelly LA. Paradoxical bronchoconstriction with short-acting Beta agonist. Am J Case Rep. 2018;19:1204-7.

56. Juniper EF, O'Byrne PM, Guyatt GH, et al. Development and validation of a questionnaire to measure asthma control. Eur Respir J. 1999;14(4):902-7.

57. Thomas M, Kay S, Pike J, et al. The asthma control test (ACT) as a predictor of GINA guideline-defined asthma control: analysis of a multinational crosssectional survey. Prim Care Respir J. 2009;18(1):41-9.

58. Kellberger J, Peters-Weist AS, Heinrich S, et al. Predictors of work-related sensitisation, allergic rhinitis and asthma in early work life. Eur Respir J. 2014; 44(3):657-65.

59. Anderson WC, Apter AJ, Dutmer CM, et al. Advances in asthma in 2016: designing individualized approaches to management. J Allergy Clin Immunol. 2017;140(3):671-80.

60. Normansell R, Kew KM, Stovold E. Interventions to improve adherence to inhaled steroids for asthma. Cochrane Database Syst Rev. 2017:4:CD012226.

\section{Publisher's Note}

Springer Nature remains neutral with regard to jurisdictional claims in published maps and institutional affiliations.

\section{Ready to submit your research? Choose BMC and benefit from:}

- fast, convenient online submission

- thorough peer review by experienced researchers in your field

- rapid publication on acceptance

- support for research data, including large and complex data types

- gold Open Access which fosters wider collaboration and increased citations

- maximum visibility for your research: over $100 \mathrm{M}$ website views per year

At BMC, research is always in progress.

Learn more biomedcentral.com/submissions 